\title{
1 Sea Surface Temperatures Drive Historical Demography of Deep-Sea
}

\section{Fishes}

3 RRH: Deep-sea Fish Demography

4

5 Max D. Weber, Joshua E. Carter, and Ron I. Eytan*

6 mweb68@tamu.edu

$7 \quad$ cart7417@tamu.edu

$8 \quad$ eytanr@tamug.edu

\section{ABSTRACT}

11 Demographic histories are largely understood to be a product of their environment, as populations

12 expand or contract in response to major environmental changes. Deep-pelagic fishes inhabit one

13 of the most temporally and spatially stable habitats on the planet, so they may be resistant to the

14 demographic instability commonly reported in other marine habitats, but their demographic

15 histories are poorly understood. We reconstructed the demographic histories of thirteen species

16 of deep-pelagic fishes using mitochondrial and nuclear DNA sequence data. We uncovered

17 widespread evidence of demographic expansion in our study species, a counterintuitive result

18 bases on the nature of the deep-pelagic. The frequency-based methods detected potential

19 demographic changes in eleven species, while the Extended Bayesian Skyline Plots were more

20 conservative and identified population expansion in five species. The dates of expansion largely

21 coincide with periods of warm sea-surface temperature at the northern and southern boundaries

22 for the ranges these species inhabit. We suggest that this is the result of the pelagic larval phase

23 shared by most deep-pelagic fishes, where the larvae inhabit the upper 200 meters. Changes in

24 sea surface conditions likely alter the suitability of the habitat in a given region for the larval 
25 phase, affecting the species range and in turn population size. These results are critical to our

26 understanding of how the deep-pelagic fish community will respond to future climatic changes.

\section{INTRODUCTION}

30 The demographic history of a species is strongly influenced by the environment it inhabits (Alheit

31 \& Hagen 1997; Avise et al. 2000; Grant 2015). Major changes in the environment can alter the

32 distribution and size of suitable habitat for a species, reducing or increasing the species'

33 range. Population sizes expand or contract in response to these fluctuations in range size (Avise

34 et al. 2000; Nye et al. 2009). Evidence for the environment's control over population dynamics

35 can be seen across taxonomic groups in terrestrial and marine habitats around the world (Almada

36 at al. 2012; Eytan \& Hellberg 2010; Grant 2015, Robalo et al. 2012).

38 Given that changes in environmental conditions strongly influence population size, species

39 inhabiting unstable environments should be characterized by unstable population sizes. On the

40 other hand, species inhabiting temporally stable environments should be less susceptible to

41 frequent population expansions or contractions due to global climatic events. Studies have

42 supported this notion, finding genetic diversity to be greater in species inhabiting more stable

43 environments than closely related species in environments more subject to change (Carnaval et al.

$44 \quad 2009$; Gugger et al. 2013).

45

46 The deep-pelagic, the marine habitat found between 200 meters in depth to approximately 100

47 meters above the sea floor, is considered one of the most temporally and spatially stable

48 environments on the planet. In terms of physical characteristics like temperature, there is a strong

49 latitudinal homogeneity in the environment that increases with depth (Robison 2009). In 
50 comparison to shallower habitats, temperature change occurs slowly over time and the magnitude

51 of change is less (Abraham et al. 2013; Clark et al. 2006; Clark et al. 2009; Levitus 2000; Levitus

52 2012; Mora et al. 2013; Robison 2009). Based on the stability of the environment and our current

53 understanding of the manner in which habitat influences demography, the population sizes of the

54 fishes inhabiting the deep-pelagic would be expected to be stable over time.

55

56 If the demographic histories of deep-pelagic fishes are not stable, it is difficult to predict which

57 physical factors could drive this instability. Insights into the historic demography of deep-sea

58 organisms are few, and have focused on deep-benthic species (Etter et al. 2005; Sakuma et al.

59 2014; Varela et al. 2012). The deep-benthic environment, benthic habitat found below 200

60 meters, is much more heterogeneous than the deep-pelagic and likely under differing

61 environmental pressures (Thurber et al. 2014).

62

63 The physical factors influencing the historical demography of marine fishes inhabiting the less

64 stable upper 200 meters are better understood. Studies have consistently shown population size

65 changes that correspond with major changes in the environment that would have far less dramatic

66 effects on the deep-pelagic. A plurality of these studies report widespread population expansion

67 in shallow-dwelling fishes following the last glacial maximum. Two factors are frequently cited

68 to explain increases in geographic range and a corresponding increase in population size: an

69 increase in global sea-surface temperatures and sea-level rise that dramatically increased in shelf

70 habitats (Avise et al. 2000; Eytan \& Hellberg 2010; Grant 2015). During this same period there

71 would have been a significantly less increase in temperatures in the deep-pelagic and the amount

72 of deep-pelagic habitat increased negligibly (Abraham et al. 2013; Clark et al. 2006; Clark et al.

73 2009; Levitus 2000; Levitus 2012; Mora et al. 2013; Robison 2009). 
75 If the demographic histories of deep-pelagic fishes are unstable it is more likely that physical

76 conditions outside of the deep-pelagic drive these dynamics. Two features of deep-pelagic fishes

77 could be responsible: diel vertical migration and a pelagic larval phase. Many deep-pelagic fish

78 species perform diel vertical migrations, a daily migration to the shallower and more variable

79 epipelagic waters (Barham 1966; Sutton 2013). An analysis of the distribution of deep-pelagic

80 fishes found that the ranges of vertically migrating species were more likely to change in

81 response to large scale changes in climate than the ranges of species that do not vertically migrate

82 (Hsieh et al. 2009). This could be a result of significantly greater heating in the upper ocean than

83 deep waters, which vertical migrators visit on a daily basis. If the changes in surface waters are

84 no longer tolerable to the vertically migrating fishes these species can no longer persist in their

85 former range. If vertical migratory behavior drives demography in deep-pelagic fishes, vertical

86 migrators will be characterized by population expansions and/or contractions, while the

87 population size of non-vertical migrators will be relatively stable over time.

88

89 Yet another explanation for unstable deep-pelagic fish populations could be the existence of a

90 pelagic larval phase in nearly all deep-pelagic fishes (Bowlin 2016; Johnson et al. 2009; Moser

91 1996). These larvae reside in the upper $200 \mathrm{~m}$ and are subjected to conditions that are more

92 variable than those experienced by the adult forms. Changing conditions in surface waters could

93 alter larval distribution and in turn affect the species range and population sizes.

95 Knowledge of the demographic history of deep-pelagic fishes serves two key purposes. First, it

96 will provide insight into the ecological processes driving population dynamics in one of the

97 world's most stable environments. This could help to bolster current theory that suggests that

98 such a stable environment should produce stable populations. Secondly, understanding how

99 deep-pelagic fishes responded to past climatic events will allow us to make predictions about how

100 they will respond to future changes in climate. This is critical given the ecological importance of 
101 midwater fishes. The deep-pelagic comprises approximately $95 \%$ of the ocean by volume, and

102 the biomass of deep-pelagic fishes is at minimum $\sim 1,000$ million tons, several orders of

103 magnitude larger than the total global commercial fisheries landings (Gjosaeter \& Kawaguchi

104 1980; Irigoien et al. 2014). Furthermore, deep-pelagic fishes are important prey items for

105 numerous commercially targeted species (Battaglia 2013; Varghese et al. 2013).

106 To better understand the demography of deep-pelagic fishes, we answered the following

107 questions: (1) Are deep-pelagic fish populations stable over time? (2) If population expansions or

108 bottlenecks are detected, can the results be explained by adult migratory habits or (3) the pelagic

109 larval phase in deep-pelagic fishes?

110

111

112

\section{METHODS}

\section{Sampling and Sequence Generation}

115 We selected thirteen deep-pelagic species that span taxonomic groups, life histories, and vertical

116 migration behavior (See Supplementary Table 2). Samples were obtained by trawling with a

117 MOCNESS net system in depth zones up to 1,500 meters in the northern Gulf of Mexico (Cook et

118 al. 2020) (Figure 1). Upon collection and identification of vouchers at sea, a $\sim 1 \mathrm{~cm}$ piece of lateral

119 muscle tissue was preserved in ethanol. Voucher specimens are housed in the Ocean Ecology Lab

120 at Nova Southeastern University.

122 We generated DNA sequence data from the mitochondrial gene cytochrome oxidase I (COI) as

123 well as three nuclear DNA exons (PLAG, ENC, and MYH). PCR was performed using Promega

124 GoTAQ (Madison, WI) (see Supplementary table for primers used). Following amplification, all

125 PCR products were cleaned using a standard PEG protocol (Glenn 2019). Amplicons

126 were Sanger-sequenced on an ABI 3730 capillary sequencer at Yale Keck Biotechnology 
127 Resource Laboratory. Sequences were cleaned and edited in Sequencher v5.1. Nuclear markers

128 were phased using Phase v2.1 to resolve heterozygous sites. The sequences were then aligned

129 using MAFFT in Generiousv9.1.8 (Kearse et al. 2012).

131 Frequency-Based Analyses

132 We calculated Tajima's D, Fu's Fs, and R2 for each marker (Fu 1997; Ramos-Onsins \& Rozas

133 2002; Tajima 1989). Comparisons of the statistical power of frequency-based tests have shown

134 that Fsand R2are the most capable of detecting population growth (Ramos-Onsins \& Rozas

135 2002). They complement one another as well, with Fs excelling at population growth detection in

136 large sample sizes, while R2 performs better with small sample sizes. A significant and large

137 negative Fs value suggests population growth, while a significant and small positive R2 value

138 indicates population growth. Tajimas's $D$ points to population growth and/or a selective sweep

139 when significant and negative.

141 All of the frequency-based tests were performed in DNAsp v6 (Rozas et al. 2017). Ambiguity

142 codes were replaced with Ns to allow for calculation in DNAsp. Tajima's $D$ is a two-tailed test,

143 so significance was initially determined by the test itself. The significance of all three tests was

144 also determined using coalescent simulations with 1000 replicates implemented in DNAsp.

\section{Gene Tree Based Analysis}

147 The second set of tests makes use of the topologies and branch lengths of gene trees to infer

148 changes in population size over time using the coalescent. We performed these analyses in

149 BEAST v2.4.7 (Bouckhaert et al. 2014) to generate Extended Bayesian skyline plots

150 (EBSPs). EBSPs utilize coalescent theory and a Markov Chain Monte Carlo Algorithm to infer

151 and visualize demographic changes in a dataset. The Bayesian skyline plot is preferable to earlier

152 skyline plot methods as it models both genealogy and demographic history simultaneously, which 
153 reduces error rates from uncertainty in estimates of node time (Heled \& Drummond 2008; Ho \&

154 Shapiro 2011).

155

156 Nuclear and mitochondrial genes were included in the analysis for each species. The chain length

157 was set to $50,000,000$ sampling every 1,000 . Initial clock rates were derived from secondarily

158 calibrated ultrametric trees based on the results of Near et al. 2013. A strict clock was set and the

159 clock rate of COI was fixed. The nuclear rates were given a normal distribution with a median

160 set to the initial clock rate. The partitioning scheme and substitution models were set based on

161 Partition Finder v2.0 results (Lanfear et al. 2012).

162

163 A second set of trees was created using the same methodology, with the exception of the selection

164 of substitution models. All partitions were set to the RBS substitution mode (Bouckaert et al.

165 2014). RBS is a reversible-jump based substitution model for nucleotide data. This substitution

166 model does not require a fixed substitution model to be assigned to each partition at the beginning

167 of the analysis. Instead, it allows five different substitution models to be explored through the

168 run, in order to find the substitution model with the best fit to the dataset.

169

170 After running in BEAST, log files for both sets of trees were inspected using Tracer v 1.7.1

171 (Rambaut et al. 2018). The most strongly supported EBSP analysis, based on ESS values, was

172 selected and used for the inference of each species' demographic history. The posterior estimate

173 of the number of population size changes provided a test for a rejection of constant population

174 size. Finally, the trees files were uploaded to Rstudio v 0.99.484 (Studio 2012). The Rscript

175 “plotEBSP”, provided with the EBSP tutorial (http://www.beast2.org/files/2016/01/ebsp2-

176 tut.zip), was used to generate and visualize the extended Bayesian skyline for the timing of

177 inferred population size change events (Heled 2010). Vertical lines were added to the plots to

178 indicate the approximate timing of the onset of population expansion. 


\section{Population Dynamics and Vertical Migration}

181 We placed species into two categories; those that had undergone an inferred population size

182 change and those that had not. Species placed into the "inferred population size change" group

183 were categorized as such if the inference was uncovered in both the frequency-based and gene

184 tree based analyses. We further divided species into vertical migrators and non-vertical

185 migrators. A chi-squared test was used to test for a correlation between inferred population size

186 changes and vertical migration. Information on the migration patterns of two fishes (Polymixia

187 lowei, and Synagrops spinosus) was unavailable, so they were left out of the analysis.

\section{Sea Surface Temperature and Population Size Changes}

190 We plotted sea surface temperatures (SST) for the past 300,000 years from the North and South

191 Atlantic based on previously published climate data (Becquey \& Gersonde 2003; Ruddiman et al.

192 1989). We selected these datasets as they provided sufficient resolution/coverage for the period

193 of time when inferred demographic changes occurred. Furthermore, the two datasets were

194 obtained from sites located approximately $41^{\circ} \mathrm{N}$ and $42^{\circ} \mathrm{S}$, corresponding to the northern and

195 southern extent of the range inhabited by many tropical/low-latitude deep-pelagic

196 species. Accordingly, changes in SST at these latitudes could directly impact the larval

197 distribution for low-latitude deep-pelagic species. We indicated the mean temperature, as well as

198 the mean temperature plus one standard deviation for this period, to identify periods that were

199 warmer than average as well as period of exceptional warmth. The dates of the onset of

200 population size change inferred from our EBSPs were mapped on the plot to allow for the

201 comparison of fluctuations in SST and population dynamics in our study species. 


\section{RESULTS}

\section{Summary}

206 The number of sequences generated for each species and marker varied according to sample

207 availability and our ability to achieve amplification. The number of unique sequences obtained

208 for each gene ranged from a low of ten to a high of 97 . We used two genes for analysis in ten

209 species, three genes in one species, and four genes in two species (Table 1). Sequences have been

210 deposited to GenBank with \#s xxxxx-xxxxx.

\section{$212 \quad$ Frequency-based analyses}

213 Frequency-based analyses suggested population expansions in 11 of our 13 sampled species

214 (Table 1). In four species (Chauliodus sloani, Sternoptyx pseudobscura, Cyclothone alba, and

215 Photostomias guernei) more than half of the frequency-based test for all markers suggested

216 population size changes. Weaker support was present in another seven species (Diplospinus

217 multistriatus, Ditropichthys storeri, Polymixia lowei, Scopelogaudus mizolepis, Sigmops

218 elongatus, Stomias affinis, and Synagrops spinosus), where less than half of the markers tested

219 produced significant results. No evidence for demographic change was present in Bathophilus

220 pawneii or Cyclothone pseudopallida.

\section{Gene Tree Based Analysis}

223 We were able to reject a constant population size in five of the thirteen species (Figure 2). We

224 inferred increases in population sizes for all of the species where a constant population size was

225 rejected. The timing of these population expansions was highly variable. Cyclothone alba

226 experienced the most recent increases in population size, which appears to have begun about 85

227 Kya. Three other species experienced population size increases 125-200 Kya (Chauliodus sloani, 
228 Photostomias guernei, and Polymixia lowei). The oldest population increase that we inferred

229 occurred approximately 270 Kya in Sternoptyx pseudobscura.

\section{Frequency-based Analyses vs EBSPs}

232 Frequency-based tests suggested population expansions in eleven species. The four species with

233 the strongest support in the frequency-based tests were all found to have undergone expansions

234 using the EBSP method. Our EBSP analyses also recovered a population expansion in Polymixia

235 lowei, which had moderate support (fewer than half of the tests were significant) in the

236 frequency-based analyses.

\section{Vertical Migration and Population Dynamics}

239 The chi-squared test did not provide support for a relationship between vertical migration and 240 population size changes (p-value 0.8190, Table 2).

\section{Sea Surface Temperature and Population Size Changes}

243 In our analysis, there were thirteen instances when the reconstructed SST in the North Atlantic

244 reached the mean temperature plus one standard deviation (Figure 3). The reconstructed SST in

245 the South Atlantic reached the mean temperature plus one standard deviation nine times. The

246 general warming and cooling trends were largely in agreement between the two sites.

248 We plotted the approximate onset of expansion for all five species that underwent demographic

249 expansion according to our Extended Bayesian Skyline Plot analyses. The population expansions

250 for Chauliodus sloani, Photostomias guernei, and Polymixia lowei all begin during periods of

251 exceptionally warm SST at both sites, where temperatures greatly exceeded the mean plus one

252 standard deviation. Cyclothone alba commences expansion during a warm period where the

253 South Atlantic temperature exceeded the mean plus one standard deviation, however it falls just 
254 outside of a similar warm period in the North Atlantic. Sternoptyx pseudboscura is an outlier in

255 this regard, and appears to take place under conditions where the SST is close to the mean for this

256 three-hundred-thousand-year period.

\section{DISCUSSION}

259 Historic changes in effective population size are frequently inferred for marine fishes and

260 attributed to major ecological events and past climatic change (Avise et al. 2000; Grant 2015).

261 Previous studies however, have largely focused on species inhabiting shallower environments that

262 are more variable over time in terms of physical conditions such as temperature in comparison to

263 the deep-pelagic. Given the stability of the deep-pelagic, populations of fishes inhabiting this

264 environment might also be stable, so that no effective population size changes would be inferred

265 from genetic examination. Nonetheless, we uncovered multiple lines of evidence suggesting

266 population expansions in five of our thirteen deep-pelagic study species, the most ancient event

267 occurring about 270 Kya. These expansions and their timings were based on our EBSPs, which

268 utilized both mitochondrial and nuclear data. Four of the five dates of population expansion

269 coincide with periods of warm sea surface temperatures (SST) at $41^{\circ}$ North and $42^{\circ}$ South in the

270 Atlantic, a transition zone for many tropical deep-pelagic species. Future changes to SST in this

271 region due to climate change would impact the distribution of deep-pelagic larvae residing in

272 surface waters, impacting deep-pelagic fish population sizes.

273

\section{Both Frequency-Based Statistics and EBSPs Recover Evidence for Population Expansions}

275 Population expansions were recovered using two different types of analyses that were largely in

276 agreement, however the EBSPs suggested fewer instances of demographic change. It is not

277 surprising that these tests would not agree in every case. Simulated datasets demonstrate that the

278 EBSP analyses are prone to false negatives when using fewer than eight loci (Heled \& 
279 Drummond 2008). Given the number of loci sequenced it seems likely that our EBSPs were

280 more conservative in their inference of population expansions than the frequency-based tests.

282 Deep-Pelagic Fish Population Dynamics Likely Shaped by Pelagic Larval Phase

283 Our widespread inference of population expansions in deep-pelagic fishes was

284 unexpected. Demographic events are typically attributed to major environmental changes that

285 alter the environment, in turn increasing or decreasing the amount of suitable habitat for a given

286 species (Avise et al. 2000; Grant 2015). Populations expand or contract in response to these

287 alterations in available habitat. Because the deep-pelagic has been a relatively stable habitat in

288 terms of its size and temperature for millions of years, it would seem likely that the demographic

289 histories of deep-pelagic fishes would be characterized by a lack of expansions/contractions

290 (Clark et al. 2009; Levitus et al. 2012; Robison 2009). Instead, we uncovered a minimum of five

291 cases of population expansion (identified by both frequency-based statistics and gene tree based

292 analysis) within the past 300,000 years.

294 We proposed two potential drivers of population size change in deep-pelagic fishes: vertical

295 migratory habits and the pelagic larval phase. Both hypotheses were based on obligate use of

296 more physically variable surface waters by the study species. Unlike the deep-pelagic, surface

297 waters are characterized by both frequent and dramatic changes in conditions such as sea surface

298 temperature (SST). While the conditions at depth may remain favorable to a species, surface

299 waters conditions could impact species distribution.

301 Our first proposed driver of demographic change focused on diel vertical migration (DVM), the

302 daily migration to surface water by deep-pelagic fishes. Hsieh et al. (2009) provides support for

303 this hypothesis as they reported the larval distribution of fish species with vertically migrating

304 adults changed more rapidly/frequently than non-vertically migrating species. This could be 
305 attributed to short-term changes in surface water conditions that impact vertically migrating

306 species but are unfelt by those adults that remain at depth. If vertical migratory habits were the

307 primary driver of population dynamics in deep-pelagic fishes, the demographic histories of

308 vertically migrating species would be characterized by population expansions/contractions, while

309 non-vertically migrating species should be stable over time. Based on our chi-squared test we

310 were unable to detect any difference in population dynamics between these two groups, and reject

311 this hypothesis.

312

313 The second mechanism we investigated was larval control over the demographic histories of

314 deep-pelagic fishes, as the larvae of most deep-pelagic fishes reside in the upper 200 meters

315 (Bowlin 2016; Johnson et al. 2009; Moser 1996). Two lines of evidence support this hypothesis:

316 long-term monitoring of larval distribution and deep-pelagic patterns of distribution.

318 Long-term monitoring efforts in transition zones between tropical and subpolar regions have

319 shown that physical conditions, such as sea surface temperature, are key predictors of larval

320 community composition. Furthermore, physical changes in these environments alter the larval

321 composition of the community (Ahlstrom 1969; Netburn \& Koslow 2018; Sassa et al. 2004;

322 Urias-Levya et al. 2018). Aceves-Medina et al. (2004) found that the distribution of larvae was

323 congruent with that of the adults. This suggests that as sea surface conditions alter larval

324 distributions, the ranges of adults would change accordingly.

325

326 The second piece of evidence for larval control on demography comes from the distribution

327 patterns of deep-pelagic fishes. Deep-pelagic fishes can broadly be classified as tropical or polar

328 species, and tend to have clear latitudinal geographic boundaries to their ranges (See

329 Supplementary Table 3 for range description of study species) (Olson 2001; Pearcy 1991; Randall

330 1981). Within oceanic basins, latitudinal differences in temperature decrease by depth. By 1000 
331 meters the temperature is a near uniform 5 degrees Celsius throughout most of the world's oceans

332 (Helfman et al. 2009; Tyus 2011). It is therefore noteworthy that even the range of non-vertically

333 migrating bathypelagic groups such as the whale fishes fit this pattern (Paxton 1989). It seems

334 unlikely that this distribution can be explained by physiological constraints on adults of these

335 species given the relative homogeneity of the environment. Rather, a given species range is

336 constrained to regions with surface waters tolerable to their larvae. If correct, we hypothesized

337 that periods of warm SST in high latitudes would increase the range of tropical deep-pelagic

338 fishes, and lead to population expansions.

340 To explore this hypothesis we compared our dates of inferred expansions to reconstructed SSTs

341 for the Atlantic at $41^{\circ}$ North and $42^{\circ}$ South. We inferred five cases of population expansion with

342 our EBSPs, and all but one appear to coincide with warm periods of SST at this site, the northern

343 and southernmost boundary for many tropical deep-pelagic fish ranges (Olson 2001). This

344 supports the notion that sea surface conditions constrain the ranges of species living far below

345 them through their larval phase, and that they have profound impacts on their population sizes. If

346 the tolerances of pelagic larvae dictate species distribution, it would explain why we were unable

347 to detect any difference between vertically migrating and non-vertically migrating adults. The

348 SST conditions present in a region will lead to a pelagic larval community that will mature into

349 adults tolerant to those conditions. In this manner, the physiological tolerances of pelagic larvae

350 seem to drive the demographic histories of deep-pelagic fishes.

352 Another interesting result was the frequency-based performance of Cyclothone pseudopallida and

353 Sigmops elongatus. These species had very little to no support for population expansions across

354 all genes. While our other study species have clearly defined low latitude distributions, these two

355 species exist well into polar waters in the northern hemisphere. It would seem that their larvae

356 have much greater tolerances for a wide range of conditions. Our hypothesis predicts that these 
357 species would be less susceptible to expansions/contractions in the face of climate change and our

358 analysis found this to be the case.

\section{Future Directions}

361 Exploration of the demographic histories of polar mesopelagic and bathypelagic fishes could

362 provide further support for our findings. If periods of warm sea surface temperatures benefit low

363 latitude species, polar species would be expected to experience population bottlenecks during

364 these times. Instead, high-latitude species would only undergo range expansion and a resultant

365 population expansion when sea surface temperatures were low. Repeating this methodology on a

366 set of polar deep-pelagic fish species could demonstrate whether this is the case.

\section{Conclusions}

369 Insights into the mechanisms that control deep pelagic-fish population dynamics are lacking. Our

370 results demonstrate that despite the long-term stability of the deep-pelagic, the population sizes of

371 the fishes that reside in this habitat are not static in nature. The dates of expansion we inferred

372 suggest that low latitude deep-pelagic fish species respond positively to an increase in sea surface

373 temperature at high latitudes. As we come to understand the environmental factors that influence

374 demographic changes in these fishes we will better be able to predict how populations of these

375 fishes will behave in the face of future climate change.

376

377

378

379

380

381 


\section{Works Cited}

385 J. P. Abraham, M. Baringer, N. L. Bindoff, T. Boyer, L. J. Cheng, J. A. Church, et al.

386 2013. A review of global ocean temperature observations: Implications for ocean heat 387 content estimates and climate change. Reviews of Geophysics 51:450-483.

388 Aceves-Medina, G., S. Jiménez-Rosenberg, A. Hinojosa-Medina, R. FunesRodríguez, R. Saldierna-Martínez, and P. Smith. 2004. Fish larvae assemblages in the Gulf of California. Journal of Fish Biology 65:832-847.

Ahlstrom, E. H. 1969. Mesopelagic and bathypelagic fishes in the California Current region. California Cooperative Oceanic Fisheries Investigations Reports 13:39-

394 Alheit, J. and E. Hagen. 1997. Long-term climate forcing of European herring and

395 sardine populations. Fisheries Oceanography 6:130-139.

396 Almada, V. C., F. Almada, S. M. Francisco, R. Castilho, and J. I. Robalo. 2012.

397 Unexpected high genetic diversity at the extreme Northern geographic limit of 398 Taurulus bubalis (Euphrasen, 1786). PLoS ONE 7:e44404.

399 Avise, J. C. 2000. Phylogeography: the history and formation of species. Harvard $400 \quad$ university press.

401 Barham, E. G. 1966. Deep scattering layer migration and composition: observations from a diving saucer. Science 151:1399-1403.

403 Battaglia, P., F. Andaloro, P. Consoli, V. Esposito, D. Malara, S. Musolino, C. Pedà, and 404 T. Romeo. 2013. Feeding habits of the Atlantic bluefin tuna, Thunnus thynnus (L. 

Research 67:97-107.

407 Becquey, S. and R. Gersonde. 2003. A 0.55-Ma paleotemperature record from the

408 Subantarctic zone: Implications for Antarctic Circumpolar Current Development.

$409 \quad$ Paleoceanography 18.1.

410 Bouckaert, R., J. Heled, D. Kühnert, T. Vaughan, C.-H. Wu, D. Xie, M. A. Suchard, A.

411 Rambaut, and A. J. Drummond. 2014. BEAST 2: a software platform for

412 Bayesian evolutionary analysis. PLoS computational biology 10:e1003537.

413 Bowlin, N. M. 2016. Ontogenetic changes in the distribution and abundance of early life 414 history stages of mesopelagic fishes off California. UC San Diego.

415 Carnaval, A. C., M. J. Hickerson, C. F. Haddad, M. T. Rodrigues, and C. Moritz. 2009.

416 Stability predicts genetic diversity in the Brazilian Atlantic forest hotspot. Science $417 \quad 323: 785-789$.

418 Clark, P. U., D. Archer, D. Pollard, J. D. Blum, J. A. Rial, V. Brovkin, A. C. Mix, N. G.

419 Pisias, and M. Roy. 2006. The middle Pleistocene transition: characteristics,

420 mechanisms, and implications for long-term changes in atmospheric pCO2.

$421 \quad$ Quaternary Science Reviews 25:3150-3184.

422 Clark, P. U., A. S. Dyke, J. D. Shakun, A. E. Carlson, J. Clark, B. Wohlfarth, J. X.

423 Mitrovica, S. W. Hostetler, and A. M. McCabe. 2009. The last glacial maximum. $424 \quad$ Science 325:710-714.

425 Cook, A., A. M. Bernard, K. M. Boswell, H. Bracken-Grissom, M. D'Elia, S. Derada, C.

426 G. Easson, D. English, R. I. Eytan, and T. Frank. 2020. A Multidisciplinary 
Approach to Investigate Deep-Pelagic Ecosystem Dynamics in the Gulf of Mexico following Deepwater Horizon. Frontiers in Marine Science 7:1122.

429 Etter, R. J., M. A. Rex, M. R. Chase, and J. M. Quattro. 2005. Population differentiation decreases with depth in deep-sea bivalves. Evolution 59:1479-1491.

431 Eytan, R. I. and M. E. Hellberg. 2010. Nuclear and mitochondrial sequence data reveal and conceal different demographic histories and population genetic processes in Caribbean reef fishes. Evolution: International Journal of Organic Evolution 64:3380-3397.

435 Fu, Y.-X. 1997. Statistical tests of neutrality of mutations against population growth, 436 hitchhiking and background selection. Genetics 147:915-925.

437 Gjøsaeter, J. and K. Kawaguchi. 1980. A review of the world resources of mesopelagic fish. Food \& Agriculture Org.

439 Grant, W. S. 2015. Problems and cautions with sequence mismatch analysis and Bayesian skyline plots to infer historical demography. Journal of Heredity 106:333-346.

442 Gugger, P. F., M. Ikegami, and V. L. Sork. 2013. Influence of late Quaternary climate $443 \quad$ change on present patterns of genetic variation in valley oak, Quercus lobata $444 \quad$ Née. Molecular Ecology 22:3598-3612.

445 Heled, J. and A. J. Drummond. 2008. Bayesian inference of population size history 446 from multiple loci. BMC Evolutionary Biology 8:289.

447 Helfman, G., B. B. Collette, D. E. Facey, and B. W. Bowen. 2009. The diversity of 448 fishes: biology, evolution, and ecology. John Wiley \& Sons.

449 Ho, S. Y. and B. Shapiro. 2011. Skyline-plot methods for estimating demographic 
history from nucleotide sequences. Molecular Ecology Resources 11:423-434.

451 Hsieh, C. H., H. J. Kim, W. Watson, E. Di Lorenzo, and G. Sugihara. 2009. Climatedriven changes in abundance and distribution of larvae of oceanic fishes in the southern California region. Global Change Biology 15:2137-2152. mesopelagic fishes biomass and trophic efficiency in the open ocean. Nature

457 Johnson, G. D., J. R. Paxton, T. T. Sutton, T. P. Satoh, T. Sado, M. Nishida, and M. Miya. 2009. Deep-sea mystery solved: astonishing larval transformations and extreme sexual dimorphism unite three fish families. Biology Letters 5:235-239.

460 Kearse, M., R. Moir, A. Wilson, S. Stones-Havas, M. Cheung, S. Sturrock, S. Buxton, A. Cooper, S. Markowitz, and C. Duran. 2012. Geneious Basic: an integrated and extendable desktop software platform for the organization and analysis of

464 Lanfear, R., B. Calcott, S. Y. Ho, and S. Guindon. 2012. PartitionFinder: combined 465 selection of partitioning schemes and substitution models for phylogenetic 466 analyses. Molecular biology and evolution 29:1695-1701.

467 Levitus, S., J. I. Antonov, T. P. Boyer, O. K. Baranova, H. E. Garcia, R. A. Locarnini, A.

468 V. Mishonov, J. Reagan, D. Seidov, E. S. Yarosh, and M.M. Zweng. 2012. World ocean 469 heat

470 content and thermosteric sea level change (0-2000 m), 1955-2010. Geophysical $471 \quad$ Research Letters 39.

472 Li, H. 2011. A new test for detecting recent positive selection that is free from the 

375.

475 Mora C, Wei C-L, Rollo A, Amaro T, Baco AR, Billett D, et al. (2013) Biotic and Human

476 Vulnerability to Projected Changes in Ocean Biogeochemistry over the 21st Century. PLoS Biol

477 11(10): e1001682. https://doi.org/10.1371/journal.pbio.1001682

478 Moser, H. G. 1996. The early life stages of fishes in the California Current Region.

479 California Cooperative Oceanic Fisheries Investigations Atlas 33:1505.

480 Near, T. J., A. Dornburg, R. I. Eytan, B. P. Keck, W. L. Smith, K. L. Kuhn, et al. 2013.

481 Phylogeny and tempo of diversification in the superradiation of spiny-rayed fishes. Proceedings

482 of the National Academy of Sciences 110:12738-12743.

483 Netburn, A. N. and J. A. Koslow. 2018. Mesopelagic fish assemblages across oceanic

484 fronts: A comparison of three frontal systems in the southern California Current

485 Ecosystem. Deep Sea Research Part I: Oceanographic Research Papers

$486 \quad 134: 80-91$.

487 Nye, J. A., J. S. Link, J. A. Hare, and W. J. Overholtz. 2009. Changing spatial

488 distribution of fish stocks in relation to climate and population size on the

489 Northeast United States continental shelf. Marine Ecology Progress Series

$490 \quad 393: 111-129$.

491 Olson, D. B. 2001. Biophysical dynamics of western transition zones: a preliminary

$492 \quad$ synthesis. Fisheries Oceanography 10:133-150.

493 Paxton, J. R. 1989. Synopsis of the whalefishes (family Cetomimidae) with descriptions

494 of four new genera. Records of the Australian Museum 41:135-206.

495 Pearcy, W. G. 1991. Biology of the transition region. NOAA Technical Report NMFS 
105:39-55.

497 Rambaut, A., A. Drummond, D. Xie, G. Baele, and M. Suchard. 2018. Posterior summarisation in Bayesian phylogenetics using Tracer 1.7. Systematic biology 67:901-904.

Ramos-Onsins, S. E. and J. Rozas. 2002. Statistical properties of new neutrality tests against population growth. Molecular biology and evolution 19:2092-2100. Pereira, and V. C. Almada. 2012. Northern refugia and recent expansion in the North Sea: the case of the wrasse Symphodus melops (Linnaeus, 1758).

508 Robison, B. H. 2009. Conservation of deep pelagic biodiversity. Conservation Biology $23: 847-858$.

510 Rozas, J., A. Ferrer-Mata, J. C. Sánchez-DelBarrio, S. Guirao-Rico, P. Librado, S. E. Ramos-

511 Onsins, and A. Sánchez-Gracia. 2017. DnaSP 6: DNA sequence polymorphism analysis of large data sets. Molecular biology and evolution 34:3299-3302.

513 Ruddiman, W. F., M. Raymo, D. Martinson, B. Clement, and J. Backman. 1989.

$514 \quad$ Pleistocene evolution: Northern hemisphere ice sheets and North Atlantic

$515 \quad$ Ocean. Paleoceanography and Paleoclimatology 4:353-412.

516 Sakuma, K., Y. Ueda, T. Hamatsu, and S. Kojima. 2014. Contrasting population

517 histories of the deep-sea demersal fish, Lycodes matsubarai, in the Sea of Japan

518 and the Sea of Okhotsk. Zoological science 31:375-382. 
519 Sassa, C., K. Kawaguchi, Y. Oozeki, H. Kubota, and H. Sugisaki. 2004. Distribution

520 patterns of larval myctophid fishes in the transition region of the western North

$521 \quad$ Pacific. Marine Biology 144:417-428.

522 Sutton, T. T. 2013. Vertical ecology of the pelagic ocean: classical patterns and new 523 perspectives. Journal of Fish Biology 83:1508-1527.

524 Tajima, F. 1989. Statistical method for testing the neutral mutation hypothesis by DNA $525 \quad$ polymorphism. Genetics 123:585-595.

526 Thurber, A. R., A. K. Sweetman, B. E. Narayanaswamy, D. O. Jones, J. Ingels, and R. Hansman. 2014. Ecosystem function and services provided by the deep sea.

$528 \quad$ Biogeosciences 11:3941-3963.

529 Tyus, H. M. 2011. Ecology and conservation of fishes. CRC press, Boca Raton, FL.

530 Urias-Leyva, H., G. Aceves-Medina, R. Avendaño-Ibarra, R. J. Saldierna-Martínez, J.

531 Gómez-Gutiérrez, and C. J. Robinson. 2018. Regionalization in the distribution of 532 larval fish assemblages during winter and autumn in the Gulf of California. Latin 533 American Journal of Aquatic Research 46:20-36.

534 Varela, A. I., P. A. Ritchie, and P. J. Smith. 2012. Low levels of global genetic

535 differentiation and population expansion in the deep-sea teleost Hoplostethus

536 atlanticus revealed by mitochondrial DNA sequences. Marine Biology 159:1049-

$537 \quad 1060$.

538 Varghese, S. P., V. S. Somvanshi, and D. K. Gulati. 2013. Ontogenetic and seasonal 539 variations in the feeding ecology of Indo-Pacific sailfish, Istiophorus platypterus 540 (Shaw, 1792) of the eastern Arabian Sea. Indian Journal of Geo-Marine Sciences $541 \quad$ 42:593-605. 
bioRxiv preprint doi: https://doi.org/10.1101/2021.07.07.451542; this version posted July 9, 2021. The copyright holder for this preprint (which

was not certified by peer review) is the author/funder, who has granted bioRxiv a license to display the preprint in perpetuity. It is made available under aCC-BY-NC-ND 4.0 International license.

542

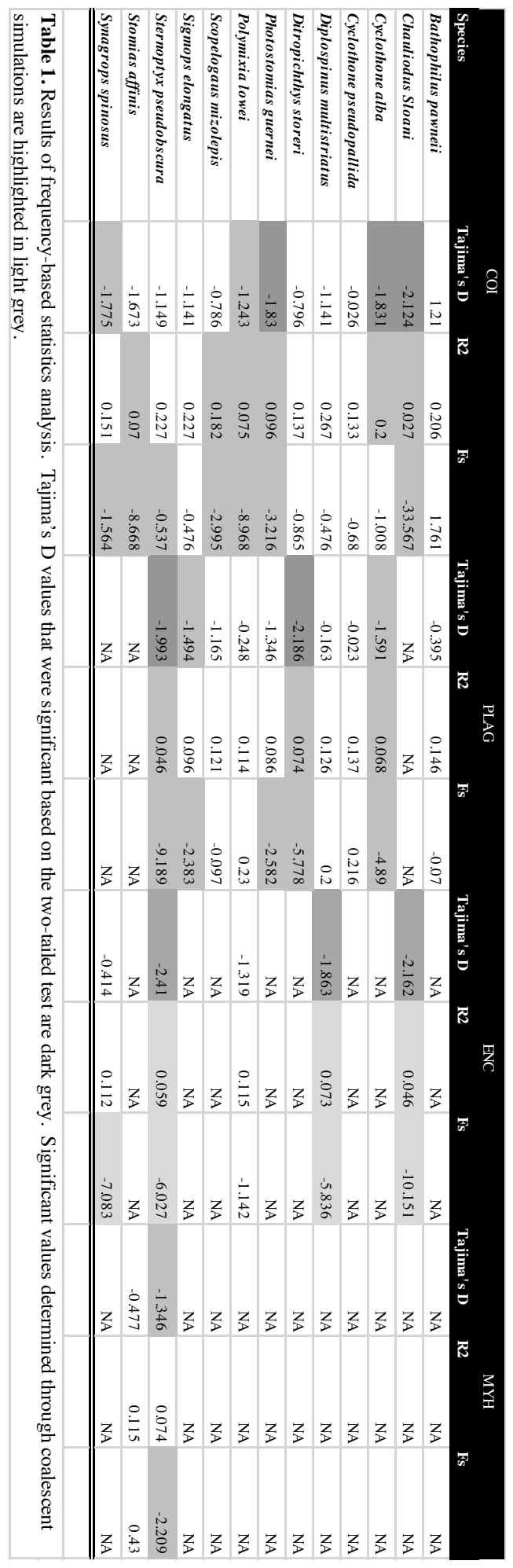


bioRxiv preprint doi: https://doi.org/10.1101/2021.07.07.451542; this version posted July 9, 2021. The copyright holder for this preprint (which was not certified by peer review) is the author/funder, who has granted bioRxiv a license to display the preprint in perpetuity. It is made available under aCC-BY-NC-ND 4.0 International license.

545

546

547

548

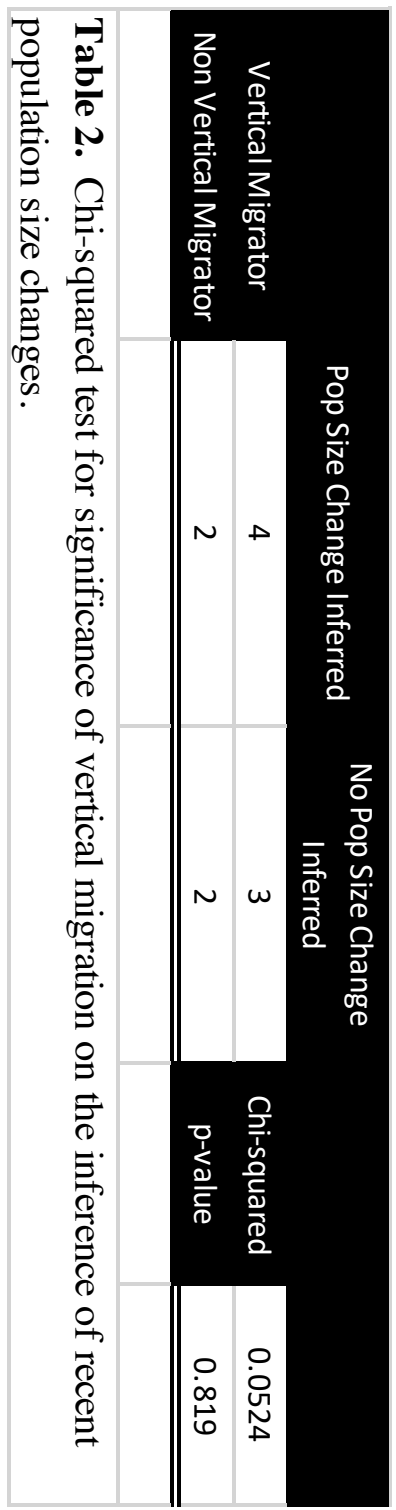

550

551 
558 Mexico. Black dots indicate stations where sampling took place.

562 The grey area displays the $95 \%$ central posterior density. The vertical black line

563 indicates the approximate onset of population expansion. 
bioRxiv preprint doi: https://doi:ger/10.1101/2021.07.07.451542; this veyion posted July 9, 2021. The copyrigt holder for this preprint (which was not certified by peer rew) is the author/funder, who has graw bioRxiv a license to display the poprint in perpetuity. It is made

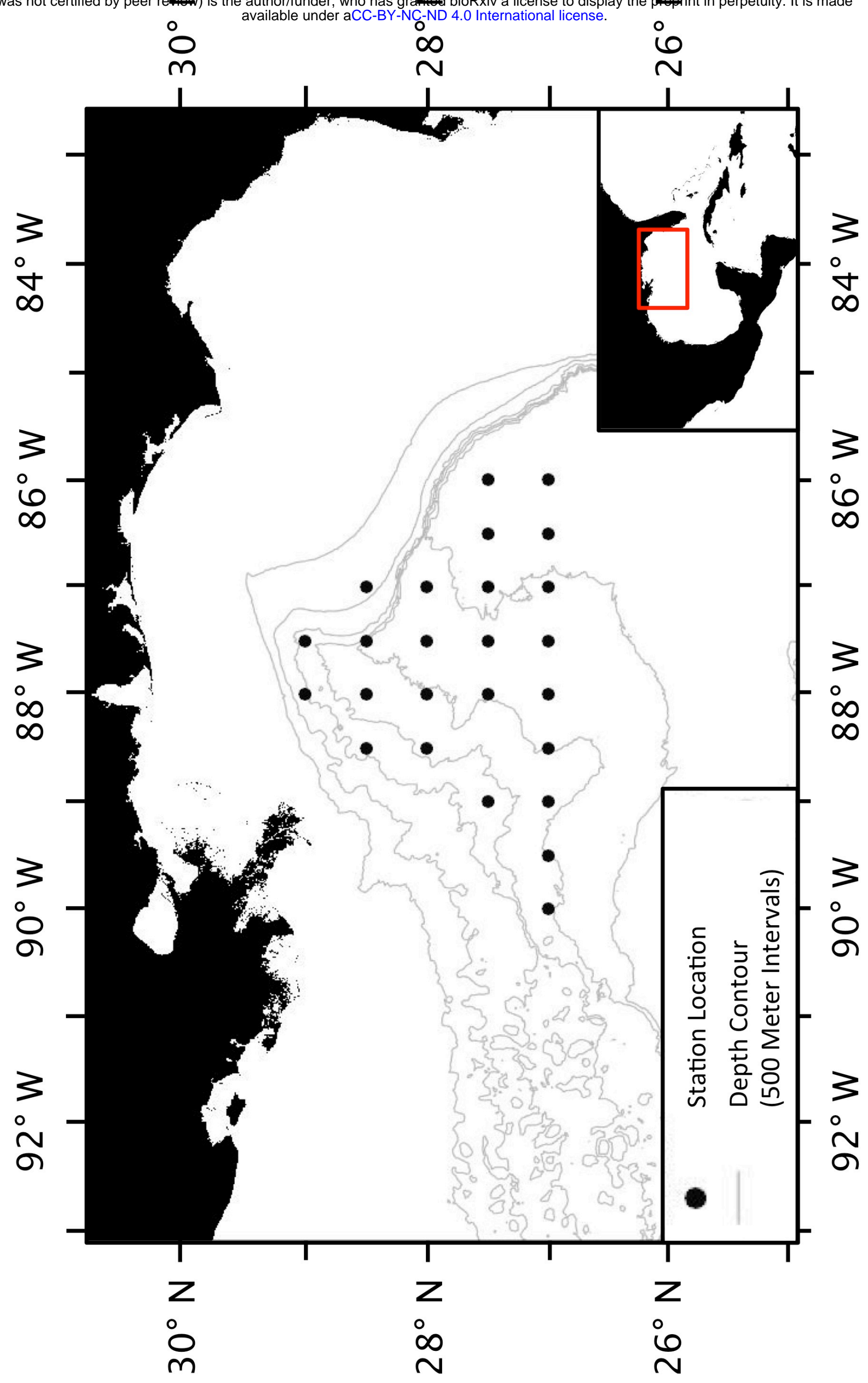




\section{Chauliodus sloani}

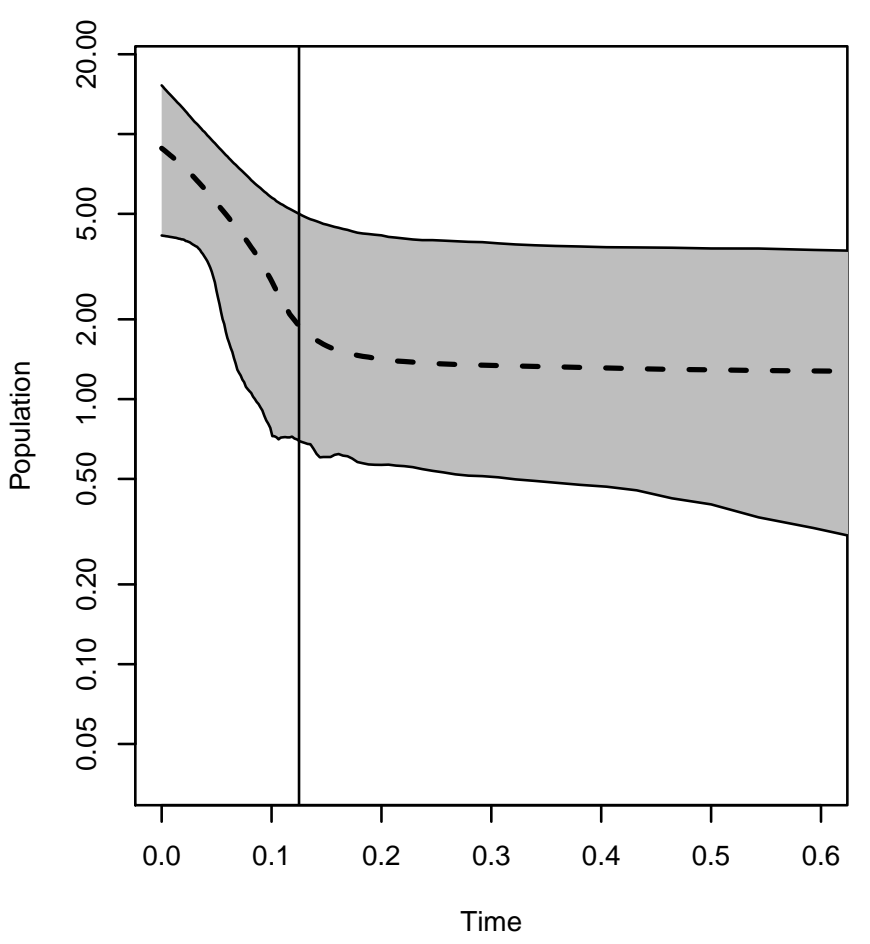

Cyclothone alba

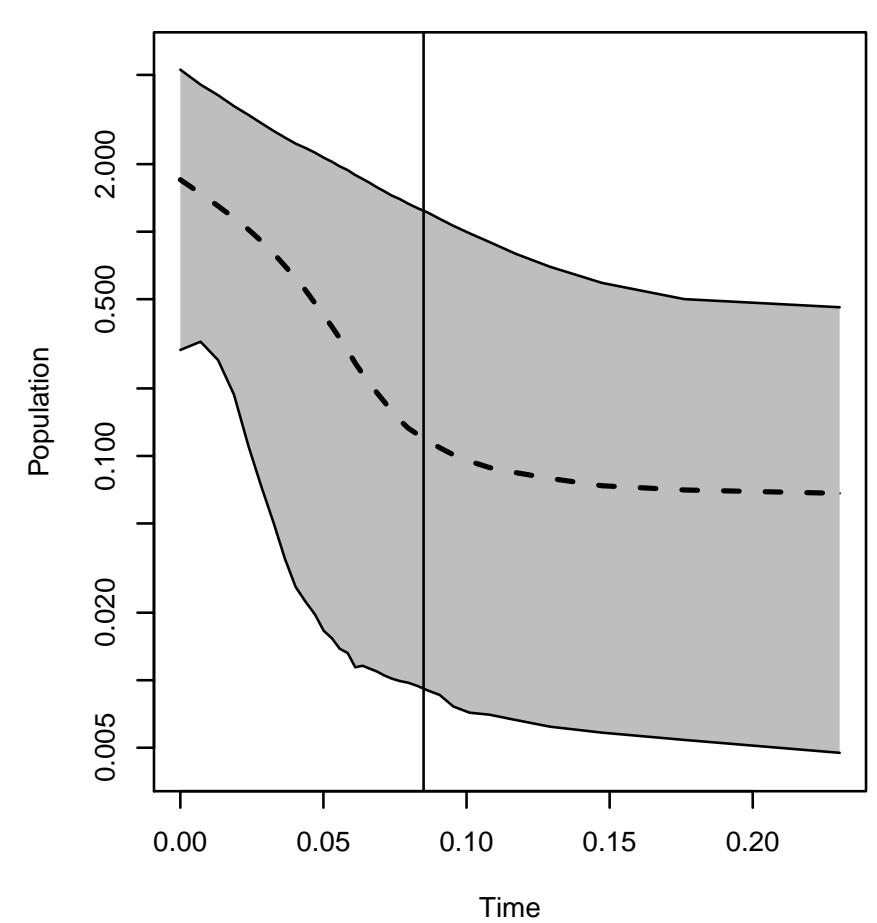

Photostomias guernei

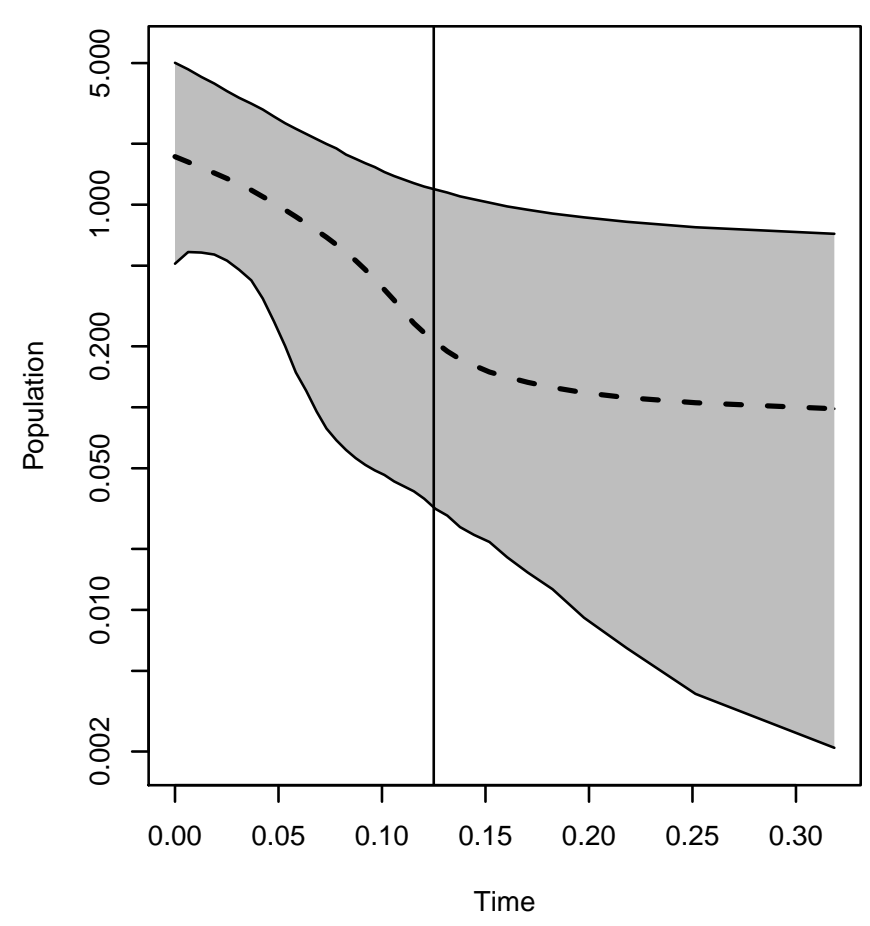

Polymixia lowei

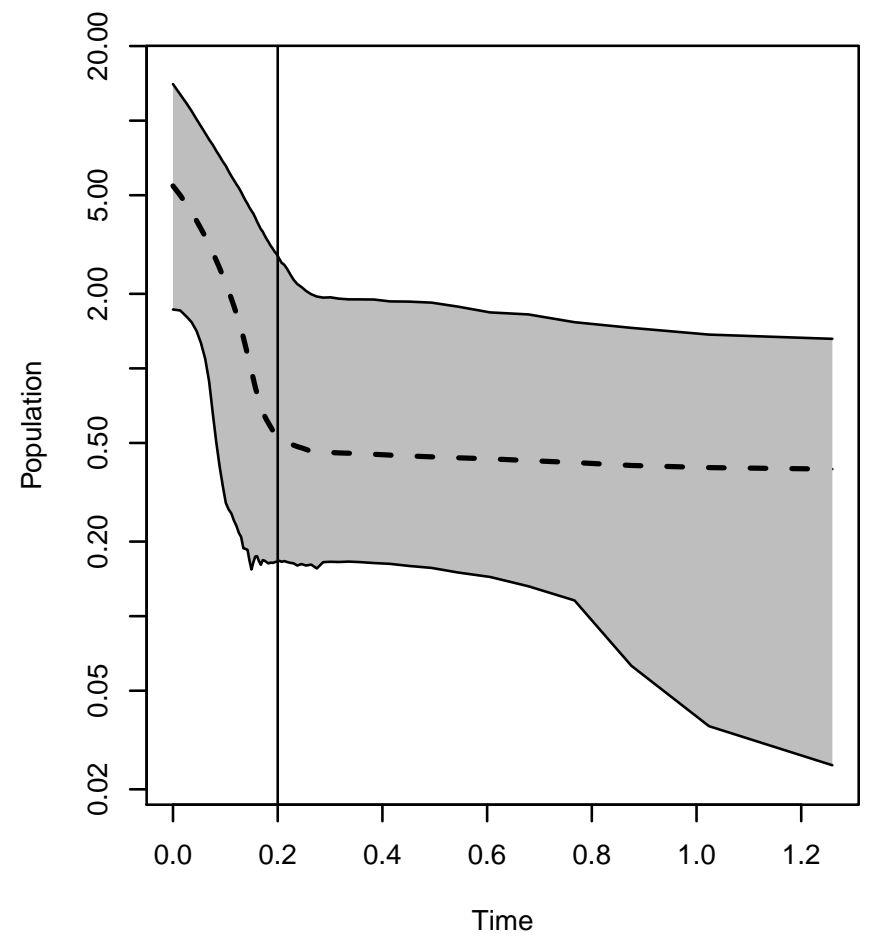

Sternoptyx pseudobscura

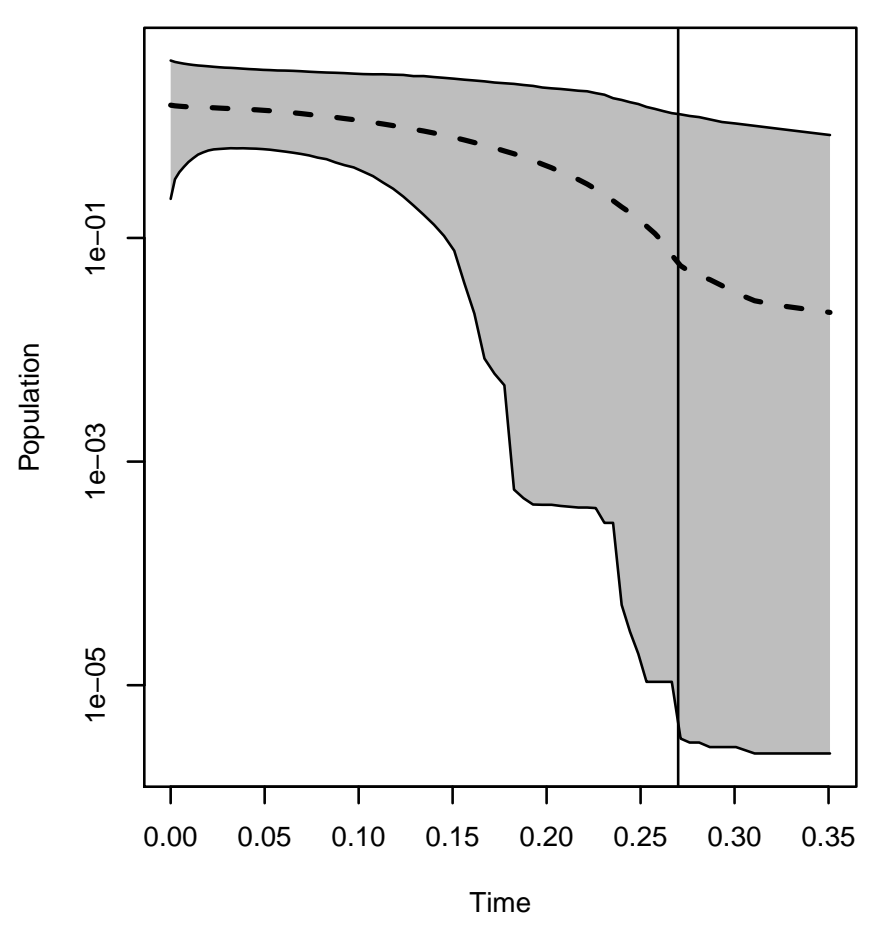


